\title{
PERANAN PENDIDIKAN TECHNOPRENEURSHIP UNTUK PEMBANGUNAN BERKELANJUTAN: STUDI KONSEPTUAL
}

\author{
Wilson Kosasih ${ }^{1}$, Ahmad ${ }^{2}$, Lithrone Laricha S. ${ }^{3}$, Didi Widya Utama ${ }^{4}$ \\ ${ }^{1,2,3)}$ Staf Pengajar Program Studi Teknik Industri, Universitas Tarumanagara, Jakarta \\ ${ }^{4)}$ Staf Pengajar Program Studi Teknik Mesin, Universitas Tarumanagara, Jakarta \\ Email:Wilsonk@ft.untar.ac.id
}

\begin{abstract}
This paper describes a technological business incubation model, developing integrated curriculum with technopreneurship education, as well as the involvement of Industrial Engineering of Tarumanagara University to create technology startup ecosystem. University holds the important role for enhancing technopreneurs in Indonesia. Academics or researchers as technology transfer agents, are responsible to disseminate technology entrepreneurship education broadly. Eventually, technological business incubator will able to accelerate commercialization of innovations or inventions from university researchs.
\end{abstract}

Keywords: technopreneurship, innovation, education.

\begin{abstract}
Abstrak
Makalah ini membahas sebuah model inkubasi bisnis berbasis teknologi, pengembangan kurikulum terintegrasi pendidikan technopreneurship, maupun keterlibatan teknik industri universitas tarumanagara untuk menciptakan ekosistem bisnis baru berbasis teknologi. Universitas memegang peranan yang penting dalam meningkatkan technopreneur di Indonesia. Akademisi atau peneliti sebagai agen pengembang maupun difusi inovasi dan teknologi, bertanggung jawab mendiseminasikan pendidikan entrepreneurship berbasis teknologi secara luas. Akhirnya, inkubator bisnis berbasis teknologi akan dapat mempercepat komersialisasi hasil inovasi atau invensi yang dihasilkan dari riset universitas.
\end{abstract}

Kata kunci: technopreneurship, inovasi, pendidikan.

\begin{abstract}
Latar Belakang
Belakangan ini, negara-negara di kawasan Asia mengalami perlambatan ekonomi bahkan ada yang mengalami krisis akibat kebijakan negara Tiongkok yang melakukan devaluasi mata uangnya dan juga rencana Bank Federal AS untuk menaikkan suku bunganya. Perekonomian Indonesia sebelumnya pernah tumbuh hingga mencapai $\pm 7 \%$, namun belakangan ini mengalami penurunan dan perlambatan hingga hanya mencapai pertumbuhan $\pm 4,5 \%$ pada tahun 2015 kuartal I. Oleh sebab itu, pemerintah RI mengeluarkan paket kebijakan ekonomi untuk menyelamatkan mata uang Rupiah dari pelemahan terhadap mata uang US Dollar. Saat ini pemerintah juga terus mendorong percepatan ekonomi indonesia dengan menitikberatkan pada akselerasi pembangunan infrastruktur maupun konektivitasnya. Jika hal itu tidak dilakukan, di era Masyarakat Ekonomi ASEAN Indonesia hanya akan menjadi sasaran pasar bagi produk-produk negara tetangga. Padahal Indonesia mempunyai kelas menengah yang kuat dan jumlahnya meningkat cukup signifikan. Ada berbagai pendapat yang menyatakan bahwa Indonesia merupakan negara raksasa yang sedang tertidur dan
\end{abstract}

sedang ditunggu untuk menjadi 5 negara dengan ekonomi besar dalam 20 tahun mendatang. Arman Hakim \& Hermawan Kertajaya dalam bukunya yang berjudul Supply Chain Economic Rekonstruksi Inovasi Daya Saing Increasing Return menyatakan bahwa "Untuk mencapai mimpi pertumbuhan ekonomi besar tersebut, yang perlu dilakukan adalah membangun lompatan daya saing bangsa, baik daya saing infrastruktur maupun daya saing sumber daya manusia yang berkarakter, inovatif, dan terdidik."

Membangun manusia yang unggul, dan responsif terhadap perubahan teknologi adalah salah satu poin penting agar bangsa ini dapat berdaya saing dan mandiri di era globalisasi. Bahkan, Michael Porter dalam penelitiannya menyatakan bahwa pendidikan formal berperan strategis dalam pembangunan nasional (Hakim \& Kertajaya, 2012 : 11). Dalam membangun kemajuan negara, diperlukan keseimbangan antara pembangunan infrastruktur maupun manusianya (pendidikan SDM-nya). Selain penelitian Porter, hal tersebut diperkuat juga oleh data Gerald W Bracey yang mengutip data national Academies, menyatakan bahwa dimana pada tahun 1990-1991 China hanya menghasilkan 200.000 sarjana teknik, ternyata 
15 tahun kemudian (2004) China telah mampu menghasilkan output 2,5 kali lipat sarjana teknik sebanyak 500.000 orang per tahun dan 600.000 orang per tahun pada tahun 2006, begitu pula India menghasilkan 350.000 sarjana teknik, sedangkan di AS terjadi deflasi lulusan teknik yang hanya 70.000 sarjana teknik per tahun (Hakim \& Kertajaya, 2012 : 12). Hal ini dipertegas data mulai tahun 2004 hingga tahun 2008 oleh Persatuan Insinyur Indonesia (PII), jumlah lulusan sarjana teknik per tahun Negara Brasil sebanyak 45.000 orang, China 600.000 orang, India 450.000 orang, Indonesia 37.000 orang, Korea Selatan 80.000 orang, Malaysia 9.900 orang, Thailand 13.000 orang, dan Vietnam 25.000 orang (seperti ditunjukkan pada Gambar 1). Jika dilihat dari jumlah lulusan maka Indonesia terlihat menghasilkan sarjana teknik lebih banyak dibandingkan negara-negara lain di kawasan Asia Tenggara. Namun, apabila dibandingkan dengan rasio per 1 juta penduduk, maka ternyata Indonesia mempunyai nilai rasio yang paling rendah dibandingkan lainnya (seperti terlihat pada Gambar 2). Artinya bahwa saat ini Indonesia mengalami kekurangan Insinyur/tenaga ahli keteknikan, terutama keahlian konstruksi. Padahal pemerintah saat ini tengah mempercepat pembangunan infrastruktur untuk mendorong pertumbuhan ekonomi nasional. Selain itu, grafik pada Gambar 2 menunjukkan bahwa ternyata Korea Selatan memiliki nilai rasio tertinggi. Oleh karena itu, tidaklah mengherankan saat ini banyak produk-produk maupun teknologi-teknologi berasal dari negeri ginseng itu. Begitu pula Negara China yang terus membangun infrastruktur dengan sangat cepat, dan juga India bahkan Vietnam. Negara-negara tersebut berhasil melakukan lompatan daya saing. Menurut Arman Hakim \& Hermawan Kertajaya, fenomena tersebut menunjukkan bahwa pendidikan, khususnya pendidikan tinggi teknik yang berorientasi entrepreneurship merupakan faktor yang menentukan keberhasilan pertumbuhan increasing, melalui kualitas kemampuan inovasi.

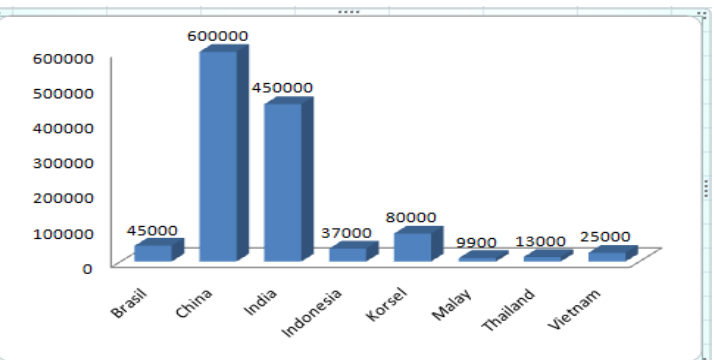

Gambar 1. Jumlah Lulusan Sarjana Teknik per Tahun (sumber: PII, 2016)

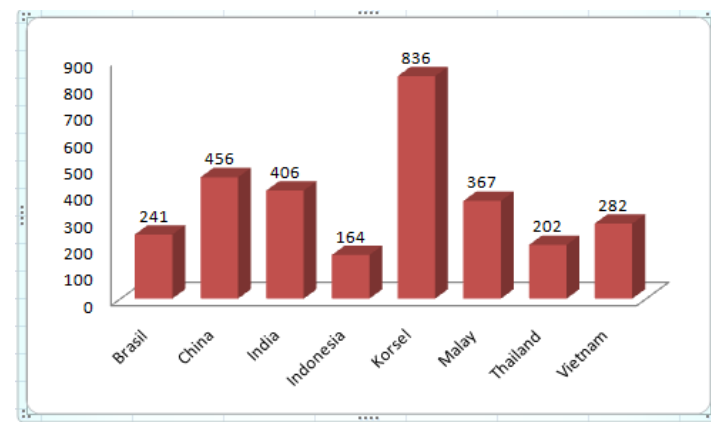

Gambar 2. Jumlah Lulusan Sarjana Teknik per Tahun per 1 Juta Penduduk untuk Populasi

Tahun 2008 (sumber: PII, 2016)

\section{Tantangan di Masa Ekonomi Berbasis Pengetahuan dan Teknologi}

Penerapan teknologi untuk hidup lebih baik atau meningkatkan kesejahteraan masyarakat menjadi salah satu aspek vital dalam mendorong pertumbuhan ekonomi suatu negara, bahkan dapat menjadi pemicu daya saing. Negara ini telah merdeka selama 71 tahun, akan tetapi bangsa ini masih mengalami penjajahan modern di sektor ekonominya. Pada periode sebelumnya, banyak kebijakan pemerintah yang justru lebih berpihak pada impor dilakukan, misalnya impor garam. Komoditi tersebut adalah satu dari banyak impor lainnya yang dilakukan, padahal indonesia mempunyai perairan yang begitu luas namun belum mampu memenuhi kebutuhan garam dari produksinya sendiri di dalam negeri. Tentunya sebuah kasus sederhana ini menunjukkan bahwa bangsa ini belum mandiri dan berdaulat dalam bidang ekonomi. Penelitian yang dilakukan oleh Stan Shih, pendiri Acer pada tahun 1996 dimana mengenalkan konsep smiling curve dalam menggambarkan nilai tambah sepanjang rantai nilai industri komputer di Taiwan, dan juga diperkuat oleh Porter, begitu pula, oleh Sutrisno (detailnya lihat Gambar 3) yang melakukan penelitian serupa namun dengan objek penelitian di level makro ekonomi juga terjadi dengan pola yang sama di level mikro (Hakim \& Kertajaya, 2012 : 63-64). Berdasarkan kurva tersebut, maka tidaklah mengherankan mengapa bangsa ini tertinggal dalam hal membangun ekonomi berbasis industri manufaktur. Padahal sumber daya alam di Indonesia sangatlah berlimpah, dimana merupakan penghasil timah terbesar kedua di dunia, penghasil kelapa sawit terbesar di dunia, penghasil karet terbesar ketiga di dunia, penghasil emas terbesar ketujuh di dunia dan masih banyak lainnya. Kapan bangsa ini mampu mencapai kemandirian dan kedaulatan ekonomi? Dan, Bagaimana? Ini yang menjadi tantangan ke depan. 


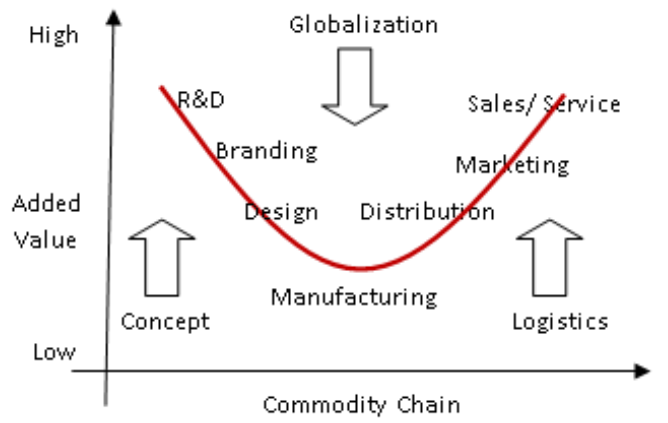

Gambar 3. Kurva Supply Chain Economic oleh Sutrisno, yang merupakan pengembangan dari Smiling Curve oleh Stan Shih

Dalam membangun negeri ini sebaiknya keterlibatan seluruh lapisan masyarakat harus terus ditingkatkan. Setiap warga negara harus turut aktif berpartisipasi dalam mengisi dan memajukan bangsa ini. Peranan generasi penerus bangsa dirasakan begitu penting mengingat saat ini persentase jumlah orang muda yang besar dan tahun 2025 Indonesia diprediksi akan mendapatkan bonus demografi. Generasi muda yang diharapkan nantinya dapat menjadi future leader. Tetapi, belakangan ini disinyalir bahwa remaja sekarang tidak banyak yang berminat menjadi seorang insinyur. Padahal telah disebutkan sebelumnya, bangsa yang berdaya saing harus menggerakkan roda perekonomian ini dengan berbasiskan pada penguasaan IPTEK.

\section{Model Inkubasi Bisnis Berbasis Teknologi}

Pada dasarnya, seorang technopreneur memiliki mindset dan karakter dari seorang entrepreneur. Entrepreneurship adalah suatu kemampuan atau keterampilan yang dapat mempergunakan dan menggabungkan seluruh sumber daya, seperti: tenaga kerja, modal, teknologi, dan lainnya untuk memaksimalkan profit yang diperoleh. Akan tetapi, technopreneurship lebih menekankan pada basis penerapan teknologi dalam menjalankan bisnisnya, khususnya pengembangan produk baru dan inovasi. Seperti dikutip dari Buku Technopreneurship oleh Direktorat Akademik, Direktorat Jendral Pendidikan Tinggi (2008), Amir Sambodo (2006) membedakan antara pelaku usaha kecil, entrepreneur tradisional, dan technopreneur dikaji dalam berbagai aspek, seperti ditunjukkan pada Tabel 1. Oleh karena itu, disebutkan bahwa technopreneur merupakan entrepreneur modern yang berbasis teknologi, dimana inovasi dan kreativitas sangat mendominasi untuk menghasilkan produk-produk unggulan di era knowledge based economic.

Tabel 1. Perbedaan antara pelaku usaha kecil, entrepreneur tradisional dan technopreneur

\begin{tabular}{|c|c|c|c|}
\hline Aspek/atribut & Pelaku usaha kecil & $\begin{array}{l}\text { Entrepreneur } \\
\text { tradisional }\end{array}$ & Technopreneur \\
\hline Motivasi & $\begin{array}{l}\text { - Sumber hidup } \\
\text { - Tingkat keamanan } \\
\text { - Bekerja sendiri } \\
\text { - Ide khusus } \\
\text { - Personaliti pemilik }\end{array}$ & $\begin{array}{l}\text { - Motivasi mendominasi } \\
\text { - Ide dan konsep } \\
\text { - Eksploitasi } \\
\text { kesempatan } \\
\text { - Akumulasi kekayaan }\end{array}$ & 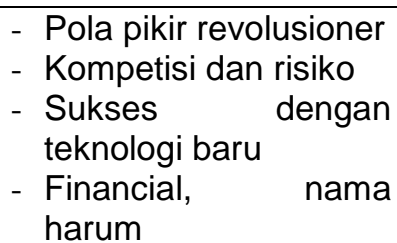 \\
\hline Kepemilikan & - Pendiri/rekan bisnis & $\begin{array}{l}\text { - Saham pengendali } \\
\text { - Maksimalisasi } \\
\text { keuntungan }\end{array}$ & $\begin{array}{l}\text { - Penguasaan pasar } \\
\text { - Saham kecil dari kue } \\
\text { besar } \\
\text { - Nilai perusahaan } \\
\text { terus bertambah }\end{array}$ \\
\hline Gaya manajerial & $\begin{array}{l}\text { - Trial and error } \\
\text { - Lebih personal } \\
\text { - Orientasi lokal } \\
\text { - Menghindari risiko } \\
\text { - Arus kas stabil }\end{array}$ & $\begin{array}{l}\text { - Mengikuti pengalaman } \\
\text { - Profesionalisme } \\
\text { - Risiko pada } \\
\text { manajemen }\end{array}$ & $\begin{array}{l}\text { - Pengalaman terbatas } \\
\text { - Fleksibel } \\
\text { - Target strategi global } \\
\text { - Inovasi produk } \\
\text { berkelanjutan }\end{array}$ \\
\hline Kepemimpinan & $\begin{array}{l}\text { - Jalan hidup } \\
\text { - Hubungan baik } \\
\text { - Dengan contoh } \\
\text { - Kolaborasi } \\
\text { - Kemenangan kecil }\end{array}$ & $\begin{array}{l}\text { - Otoritas tinggi } \\
\text { - Kekuatan lobi } \\
\text { - Imbalan untuk } \\
\text { kontribusi } \\
\text { - Manajemen baru }\end{array}$ & $\begin{array}{l}\text { - Perjuangan kolektif } \\
\text { - Sukses masa depan } \\
\text { visioner } \\
\text { - Membagi kemajuan } \\
\text { bisnis } \\
\text { - Menghargai kontribusi } \\
\text { dan pencapaian }\end{array}$ \\
\hline Tenaga kerja & $\begin{array}{l}\text { - Jaminan rendah } \\
\text { - Kekeluargaan } \\
\text { - Risiko tinggi }\end{array}$ & $\begin{array}{l}\text { - Merekrut lokal dan } \\
\text { global } \\
\text { - Kompensasi menarik } \\
\text { - Mobilitas rendah }\end{array}$ & $\begin{array}{l}\text { - Multikultural kualitas } \\
\text { tinggi } \\
\text { - Berasal dari PT } \\
\text { ternama dan lembaga } \\
\text { riset }\end{array}$ \\
\hline
\end{tabular}




\begin{tabular}{|c|c|c|c|}
\hline Aspek/atribut & Pelaku usaha kecil & $\begin{array}{c}\text { Entrepreneur } \\
\text { tradisional }\end{array}$ & Technopreneur \\
\hline & & & $\begin{array}{l}\text { - Insinyur muda, tertarik } \\
\text { IPO, M\&A } \\
\text { - Finansial, nama } \\
\text { harum }\end{array}$ \\
\hline $\begin{array}{l}\mathrm{R} \& \mathrm{D} \\
\text { Inovasi }\end{array}$ & $\begin{array}{l}\text { - Mempertahankan } \\
\text { bisnis } \\
\text { - Pemilik bertanggung } \\
\text { jawab } \\
\text { - Siklus waktu yang } \\
\text { lama } \\
\text { - Akumulasi teknologi } \\
\text { sangat kecil }\end{array}$ & $\begin{array}{l}\text { - Bukan prioritas utama, } \\
\text { kesulitan } \\
\text { mendapatkan peneliti } \\
\text { - Mengandalkan } \\
\text { franchise, lisensi }\end{array}$ & $\begin{array}{l}\text { - Memimpin dalam riset } \\
\text { dan inovasi, IT, biotek } \\
\text { global } \\
\text { - Akses ke sumber } \\
\text { teknologi } \\
\text { - Bakat sangat tinggi } \\
\text { - Kecepatan } \\
\text { peluncuran produk ke } \\
\text { pasar }\end{array}$ \\
\hline $\begin{array}{l}\text { Outsourcing dan } \\
\text { jaringan kerja }\end{array}$ & $\begin{array}{l}\text { - Sederhana } \\
\text { - Lobi bisnis langsung }\end{array}$ & $\begin{array}{l}\text { - Penting tapi sulit } \\
\text { mendapatkan tenaga } \\
\text { ahli } \\
\text { - Kemampuan umum } \\
\text { - Tidak selalu tersedia } \\
\text { pada tingkat global }\end{array}$ & $\begin{array}{l}\text { - Pengembangan } \\
\text { bersama tim } \\
\text { outsourcing } \\
\text { - Banyak penawaran } \\
\text { - Science and } \\
\text { technology park }\end{array}$ \\
\hline $\begin{array}{l}\text { Potensial } \\
\text { pertumbuhan }\end{array}$ & $\begin{array}{l}\text { - Siklus ekonomi } \\
\text { - Stabil }\end{array}$ & $\begin{array}{l}\text { - Penetrasi nasional } \\
\text { cepat, global lambat } \\
\text { - Pemimpin pasar } \\
\text { dalam waktu singkat } \\
\text { dengan proteksi, } \\
\text { monopoli, oligopoli }\end{array}$ & $\begin{array}{l}\text { - Pasar berubah } \\
\text { dengan teknologi baru } \\
\text { - Akuisisi teknologi } \\
\text { - Aliansi global untuk } \\
\text { mempertahankan } \\
\text { pertumbuhan }\end{array}$ \\
\hline Target pasar & $\begin{array}{l}\text { - Lokal } \\
\text { - Kompetisi dengan } \\
\text { produk di pasar } \\
\text { - Penekanan biaya }\end{array}$ & $\begin{array}{l}\text { - Penguasaan pasar } \\
\text { nasional } \\
\text { - Penetrasi pasar } \\
\text { memakan waktu lama } \\
\text { - Produk baru untuk } \\
\text { pelangan baru }\end{array}$ & $\begin{array}{l}\text { - Pasar global sejak } \\
\text { awal } \\
\text { - Jaringan science and } \\
\text { technology park } \\
\text { - Penekanan time to } \\
\text { market, presale and } \\
\text { postsale } \\
\text { - Mendidik konsumen } \\
\text { teknologi baru }\end{array}$ \\
\hline
\end{tabular}

Sumber: Amir Sambodo, Makalah Seminar Pengembangan Technopreneurship, Jakarta 10 Agustus 2006.

$\mathrm{Di} \quad$ Indonesia pengembangan technopreneurship memerlukan sinergi dan kolaborasi antara ketiga pilar yakni: Akademisi, Pebisnis, dan Pemerintah, yang dikenal dengan sebutan The Triple Helix Technopreneurship Model. Peranan Akademisi diharapkan dapat mengembangkan invensi atau inovasi baru dan mendiseminasikan pendidikan entrepreneurship berbasis teknologi secara luas. Mowery \& Shane (2002) mendefinisikan academic entrepreneurship sebagai proses kepemimpinan dari penciptaan nilai melalui tindakan-tindakan temuan, pembaharuan, dan inovasi baik di dalam atau di luar universitas yang menghasilkan riset dan teknologi yang mampu dikomersialisasi. Sedangkan peranan pebisnis diharapkan dapat berinvestasi dan meng-coaching para pebisnis startup, dan pemerintah diharapkan dapat memberikan stabilitas/iklim berinvestasi yang baik, merumuskan kebijakan ekonomi yang dapat mendorong UMKM di Indonesia, maupun mempercepat pembangunan infrastruktur dan kawasan pengembangan sains \& teknologi. Menurut Amboala \& Richardson (2016), suatu cara yang efektif dalam mempercepat komersialisasi hasil inovasi atau invensi dari suatu universitas yaitu mengelola sebuah kerangka technopreneurship (technological entrepreneurship), yang membantu eksekusi kesepakatan perjanjian antara universitas dan industri dalam tujuan komersialisasi. Hal itu merujuk pada penelitian Rubin et.al. (2015) tentang sebuah studi mengenai komersialisasi riset pada program inkubator bisnis berbasis teknologi di Australia dan Israel. Model yang diusulkan memperlihatkan perbandingan antara hubungan tiga stakeholders utama meliputi: 1) Technological Knowledge Bearer (inventors, universitas, dan lainnya), 2) Market Knowledge Bearer, dan 3) Financial Knowledge Bearer. Penelitian tersebut menghipotesiskan bahwa aliran pengetahuan menjadi sebuah katalisator untuk komersialisasi dari hasil inovasi sebuah universitas. Dan, interaksi - komunikasi - 
kolaborasi dari semua pemangku kepentingan tersebut mengendalikan aliran pengetahuan pada inkubator bisnis berbasis teknologi. Artinya, hasil invensi atau inovasi di universitas harus sejalan dengan pasar atau pun mampu memberikan manfaat secara langsung pada masyarakat. Riset universitas sering kali tidak marketable atau tidak "berdaya jual", bahkan orientasi riset cenderung tidak sejalan dengan kebutuhan pasar. Dan juga hasil riset atau inovasi universitas yang potensi komersialisasi masih sangat jarang yang dipatenkan atau didaftarkan mendapatkan perlindungan hak kekayaan intelektual. Dibandingkan dengan Negara-negara ASEAN lainnya seperti Singapura, Malaysia, Thailand, jumlah pendaftaran paten Indonesia masih relatif sedikit. Tentunya semua hal itu perlu didorong sehingga iklim atau budaya berinovasi dapat terus ditingkatkan.

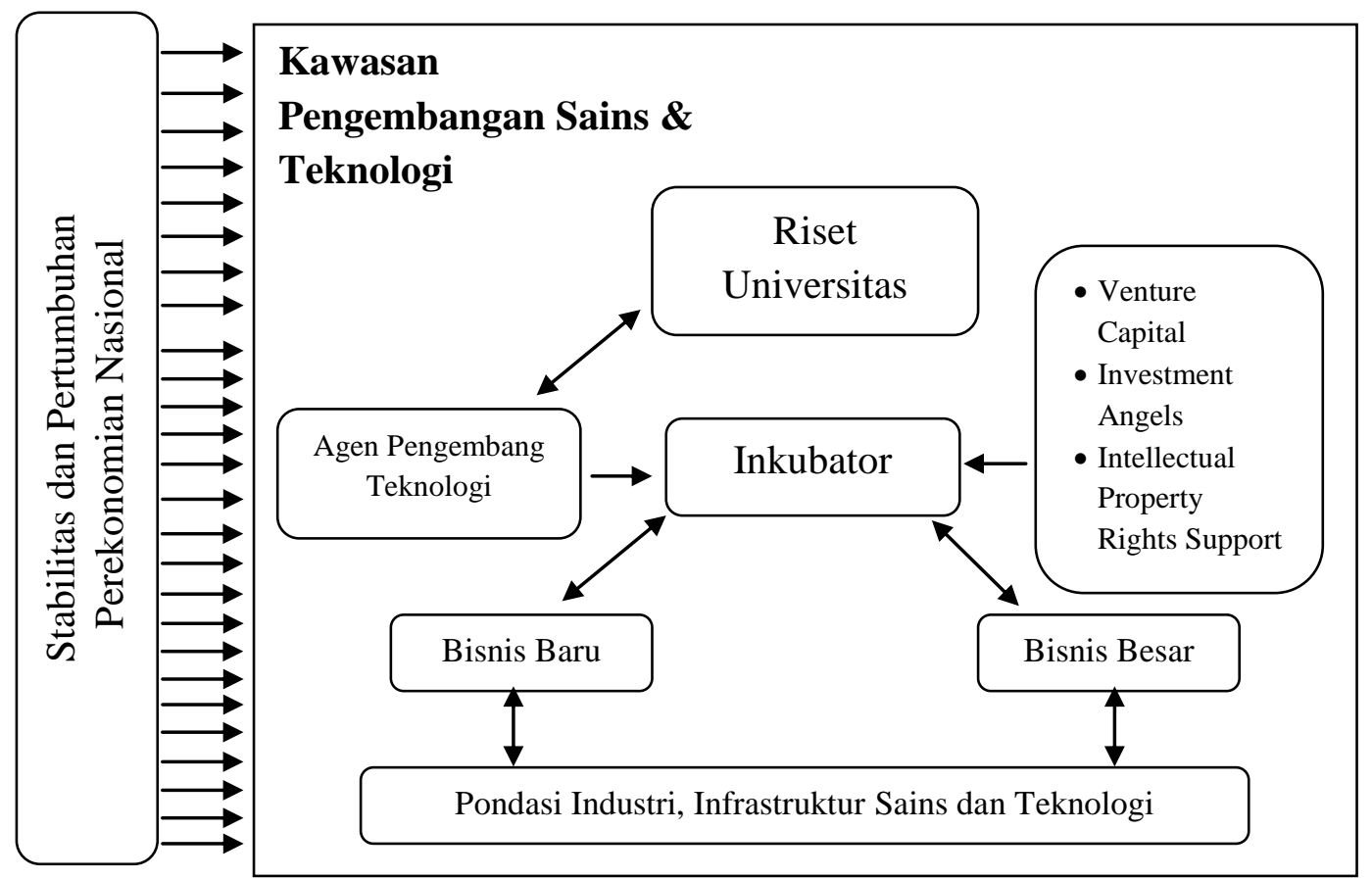

Gambar 4. Konsep inkubasi bisnis berbasis teknologi (diadaptasikan dari studi OECD, 1997)

\begin{abstract}
Inkubator bisnis berbasis teknologi dianggap sukses apabila mampu menghasilkan bisnis baru, dapat mengurangi pengangguran, terjadi difusi teknologi, meningkatkan profit untuk semua pemangku kepentingan, dan terjadi peningkatan pemasukan negara akan pajak. Studi OECD (1997) menunjukkan bahwa setiap negara mempunyai target dari inkubator teknologi yang berbeda-beda. Di beberapa negara Eropa seperti Belgia, Spanyol, Perancis, pada awalnya (tahun 1980-an s.d. tahun 1990-an) inkubator dikembangkan dengan target pengembangan cabang dari perusahaan multinasional. Sedangkan, pengembangan inkubator teknologi di Jerman, pada awalnya (tahun 1997), menargetkan untuk menghasilkan innovative-startup dan entrepreneur. Di jepang pada akhir tahun 1980-an, Inkubator teknologi menghasilkan perusahaan-perusahan kecil atau industriindustri kecil yang merupakan subsidiary dari industri besar berbasis teknologi. Sekarang ini,
\end{abstract}

pemerintah sedang gencar mengembangkan pusat pendidkan dan teknologi seperti Solo Technopark, Bandung Technopark, dan lainnya. Nantinya Science and Technology Park tersebut diharapkan akan menjadi cikal bakal Silicon Valley di Indonesia. Pengembangan dari kawasan/pusat sains dan teknologi harus disesuaikan dengan potensi lokal dan kebijakan perekonomian nasional secara menyeluruh. Tabel 2 memperlihatkan evolusi dari perkembangan science and technology park dari basis produksi industri menuju pengembangan teknologi. Dalam memenuhi targetnya, inkubator teknologi perlu memiliki: 1) infrastruktur fisik, 2) bantuan aspek manajemen, 3) bantuan aspek teknis, 4) akses keuangan, 5) layanan hukum, dan 6) jejaring. Inkubator teknologi membantu perusahaan kecil yang berbasis pengetahuan dan teknologi dalam hal keuangan, hak kekayaan intelektual, begitu pula komersialisasinya. 
Tabel 2. Perkembangan dari Science and Technology Park

\begin{tabular}{|l|c|c|c|c|c|c|c|}
\hline \multicolumn{1}{|c|}{ Institusi } & Universitas & $\begin{array}{c}\text { Fasilitas } \\
\text { riset }\end{array}$ & $\begin{array}{c}\text { Fasilitas } \\
\text { produksi }\end{array}$ & $\begin{array}{c}\text { Kantor } \\
\text { transfer } \\
\text { teknologi }\end{array}$ & $\begin{array}{c}\text { Fasilitas } \\
\text { taman }\end{array}$ & Inkubator & $\begin{array}{c}\text { Modal } \\
\text { usaha }\end{array}$ \\
\hline $\begin{array}{l}\text { Science and } \\
\text { research } \\
\text { park }\end{array}$ & $\mathrm{x}$ & $\mathrm{x}$ & 0 & $\mathrm{x}$ & $\mathrm{x}$ & $\mathrm{x}$ & 0 \\
\hline $\begin{array}{l}\text { Innovation } \\
\text { centre }\end{array}$ & $\mathrm{0}$ & $\mathrm{0}$ & $\mathrm{x}$ & $\mathrm{x}$ & $\mathrm{0}$ & $\mathrm{x}$ & $\mathrm{0}$ \\
\hline $\begin{array}{l}\text { Technopolis/ } \\
\text { Technology } \\
\text { park }\end{array}$ & $\mathrm{x}$ & $\mathrm{x}$ & $\mathrm{x}$ & $\mathrm{x}$ & $\mathrm{x}$ & $\mathrm{x}$ & $\mathrm{x}$ \\
$\begin{array}{l}\text { catatan: } \\
\mathrm{x}=\text { fasilitas esensi/mendasar. } \\
\mathrm{o}=\text { fasilitas yang diinginkan, dapat diakses melalui infrastruktur sains \& teknologi dan industri }\end{array}$ \\
\hline
\end{tabular}

Sumber: OECD, 1997

\section{Pengembangan Kurikulum Terintegrasi Pendidikan Technopreneurship dan Inovasi}

Fokus dari pengembangan pendidikan entrepreneuship berbasis teknologi adalah kreativitas dan inovasi. Kreativitas teknologi menciptakan perspektif/ide/gagasan baru/metode efektif dan efisien yang berkaitan langsung dengan proses improvement dalam perkembangan knowledge based economy. Kreativitas menjadi aspek vital dalam pengembangan riset multidisiplin maupun praktik ekonomi. Oleh karena itu, pengembangan kreativitas dalam konteks pendidikan di Indonesia sekarang ini menjadi sangat penting. Sedangkan, inovasi merupakan implementasi dari kreativitas. Inovasi teknologi berhubungan langsung dengan pemikiran, penerapan, dan penciptaan teknologi dalam penyelesaian berbagai masalah. Miller, et.al. (2012), dalam Innovation Leadership Study, melakukan sebuah survei mengenai aspek-aspek yang menentukan strategi inovasi. Hasil survei menunjukkan $80 \% \quad(\mathrm{~N}=98$ responden) bahwa strategi inovasi harus sejalan dengan strategi korporasi. Aspek lainnya yang menempati urutan kedua dan ketiga adalah teknologi (64\%) dan pasar (62\%). Selain itu, aspek lainnya yang mempengaruhi strategi inovasi diantaranya: budaya inovasi (58\%), proses inovasi $(55 \%)$, kapabilitas internal (47\%), target (44\%), dan mitra (40\%). Meskipun aspek "mitra" yang terendah berpengaruh terhadap strategi inovasi, namun kemampuan untuk bekerja secara efektif dengan mitra eksternal akan membedakan antara leader inovasi baru dan follower. Horth \& Vehar dari Center for Creative Leadership (2014) mempublikasikan sebuah studi yang menyatakan bahwa terdapat perbedaan antara innovative thinking dan traditional business thinking. Center for Creative Leadership menyatakan bahwa

"Innovative thinking is a crucial addition to traditional business thinking. It allows you to bring new ideas and energy to your role as leader and paves the way to bring more innovation into your organization."

Tidak sama dengan business thinking, seorang leader yang berpikir inovatif tidak bersandar pada pengalaman masa lalunya. Akan tetapi, innovative thinking selalu berorientasi melihat ke depan (a desirable future state). Innovative thinking menggunakan intuisi dan berpegang pada semua kemungkinan yang ada, bahkan bersandar pada ambiguitas sebagai kelebihan (detilnya dapat dilihat pada Tabel 3).

Tabel 3. Innovative Thinking vs. Traditional Business Thinking

\begin{tabular}{|l|l|}
\hline Traditional Business Thinking & Innovative Thinking \\
\hline Logis & Intuisi \\
\hline Alasan deduktif dan induktif & Alasan abduktif \\
\hline Memerlukan pembuktian proses & Bertanya "bagaimana jikalau" \\
\hline Mencari keteladanan & Tidak bersandar pada masa lalu \\
\hline Cepat memutuskan & Membuka semua kemungkinan yang ada \\
\hline Ada yang benar atau salah & Selalu ada cara lebih baik \\
\hline Tidak nyaman dengan ambiguitas & Bersandar pada ambiguitas \\
\hline Menginginkan "hasil" & Menginginkan "makna" \\
\hline Sumber: CCL, 2014 &
\end{tabular}

Penyelenggaraan proses pembelajaran untuk menghasilkan lulusan yang mampu berinovasi dan berwirausaha, menerapkan learning by doing. Sebagai contoh National University of Singapore, sebagai salah satu universitas yang berbasis pada riset dan 
pengembangan Entrepreneurship kelas dunia, mengembangkan sebuah Design Centric Program (DCP) yang mengolaborasikan seluruh departemen di Fakultas Teknik. Berdasarkan smiling curve yang disebutkan sebelumnya, sebuah negara maju meletakkan design thinking sebagai sentral inovasi sehingga pembangunan dapat berkelanjutan. Program tersebut menerapkan project based learning (multi-year duration projects) sehingga nantinya mampu menghasilkan lulusan yang mempunyai kompetensi praktis dan siap untuk bekerja. DCP mengerjakan proyek-proyek multidisiplin dan melibatkan praktisioner dan pemangku kepentingan lainnya. DCP menawarkan proyek-proyek dengan 5 tema besar, antara lain: aerospace systems initiative, future transportation systems, engineering in medicine, smart \& sustainable cities, innovative systems. Bahkan, program ini diintegrasikan dengan community service learning dalam kurikulumnya, misalnya proyek yang dikerjakan berhubungan langsung dengan permasalahan yang ada di masyarakat (social innovation project).

Begitu pula, Teknik Industri Universitas Tarumanagara menyelenggarakan project based learning yang berorientasi pada technological entrepreneurship. Proyek tersebut terdiri dari 4 tahap yang terintegrasi satu sama lainnya, yakni: 1) Proyek \#1: Innovative Product Design and Development, 2) Proyek \#2: Prototype and New Technology Venture Creation, 3) Proyek \#3: Business Process and Industrial Feasibility Study, 4) Proyek \#4: Commercialisation. Setiap proyek dikerjakan dalam kurun waktu 1 semester. Penilaian setiap proyek didasarkan pada beberapa aspek dengan Bloom's Taxonomy Approach, dan setiap tim mahasiswa akan mempresentasikan di hadapan para penguji. Gambar 5 dan Gambar 6 memperlihatkan salah satu hasil prototipe dari pengembangan produk di tahun yang berbeda.

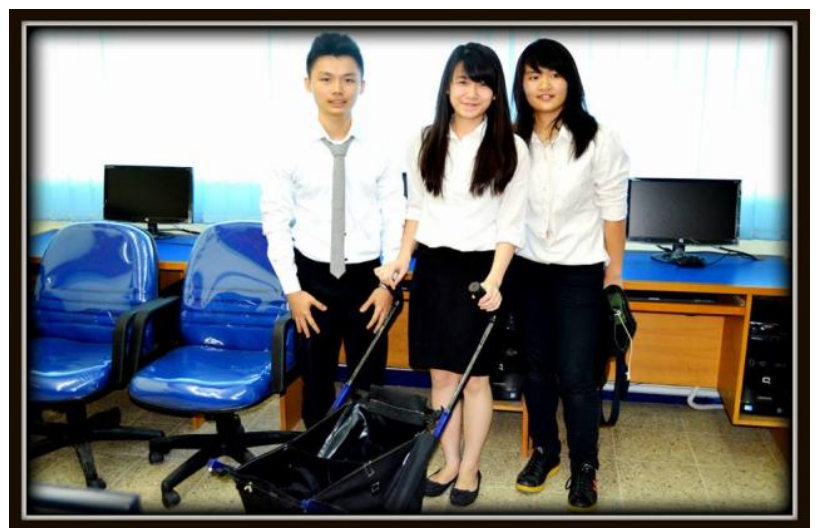

(i)

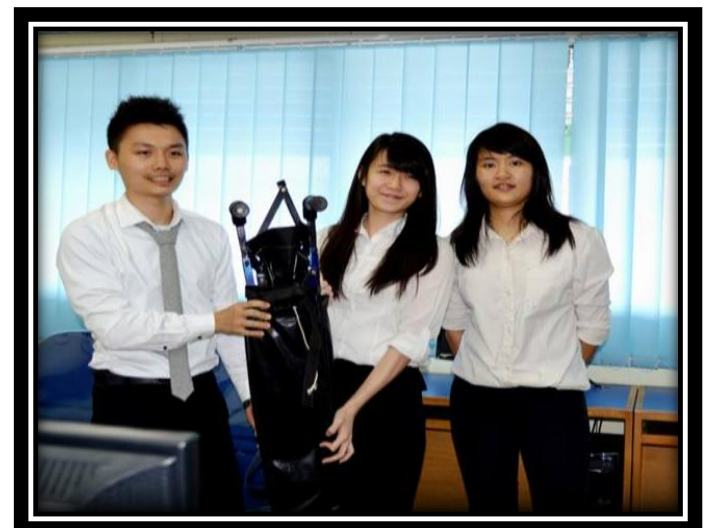

(ii)

Gambar 5. Hasil Prototipe Desain dan Pengembangan Produk Trolley, 2014: (i) kondisi dibuka, (ii) kondisi dilipat.

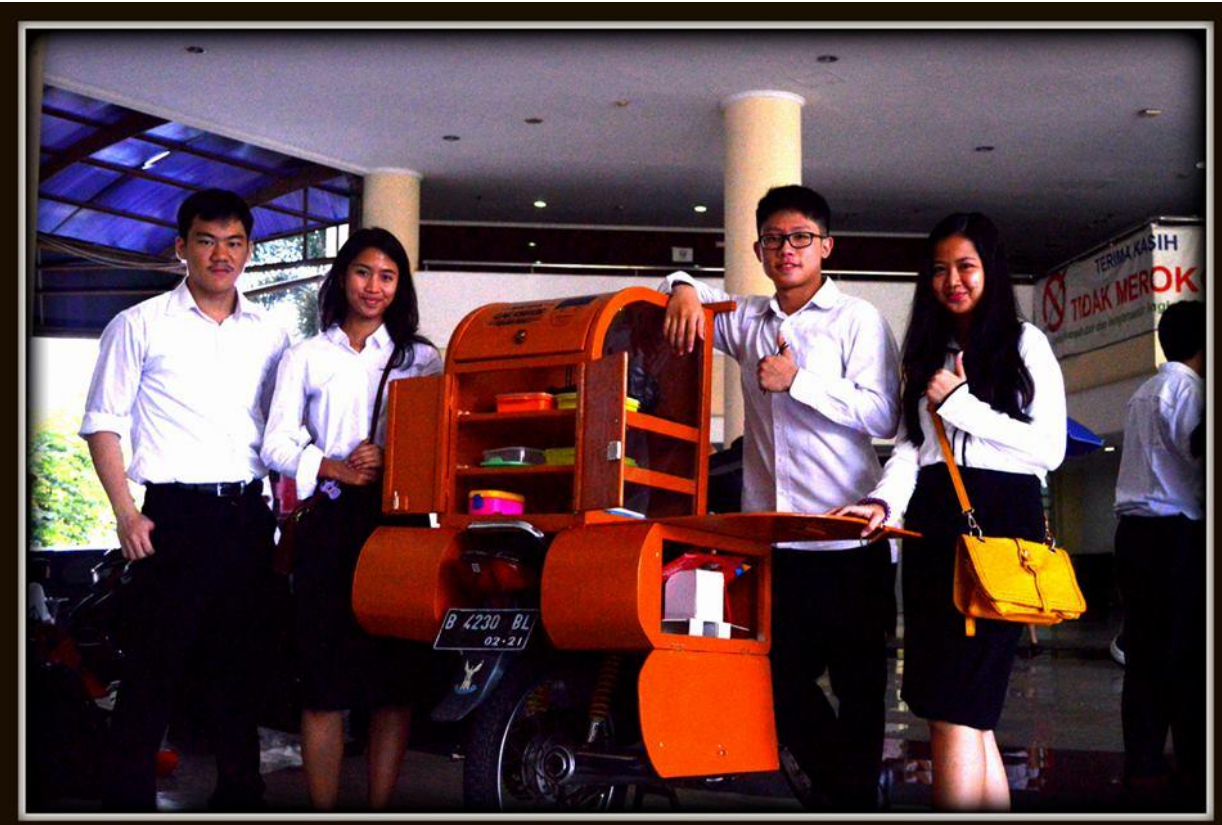

Gambar 6. Hasil Prototipe Desain dan Pengembangan Produk Gerobak Motor, 2016 


\section{Keterlibatan UNTAR dalam membangun Ekosistem Bisnis Startup Berbasis Teknologi di Indonesia}

Teknik Industri Universitas Tarumanagara ingin terlibat secara aktif dalam mendorong munculnya bisnis startup berbasis teknologi maupun menumbuh-kembangkan usaha mikro kecil menengah (UMKM). Dalam membangun ekosistem bisnis startup berbasis teknologi, Teknik Industri Universitas Tarumanagara berkolaborasi dan bekerja sama dengan berbagai pihak, diantaranya: Solo Technopark, SMAN 1 Tanjung Pandan, dlsb., dalam menyelenggarakan lokalatih dan workshop yang dapat meningkatkan dan mengenalkan technopreneurship di berbagai lapisan masyarakat. Sosialisasi dan lokalatih itu telah diselenggarakan di empat tempat yang berbeda, yaitu: Tanjung Pandan Belitung, Solo, Bandung maupun Semarang.

Tabel 4. Materi Lokalatih Technopreneurship dan Workshop Autodesk Fusion 360

\begin{tabular}{|c|c|c|c|}
\hline No. & Pokok Bahasan & $\begin{array}{c}\text { Materi/ } \\
\text { Sub-Pokok Bahasan }\end{array}$ & KOMPETENSI \\
\hline 1. & $\begin{array}{l}\text { Pengenalan } \\
\text { Technopreneurship }\end{array}$ & $\begin{array}{ll}\text { 1. } & \text { Pengertian } \\
\text { Technopreneurship } \\
\text { 2. Innovative thinking vs. } \\
\text { business thinking } \\
\text { 3. Supply chain economic } \\
\text { 4. Membangun mentalitas } \\
\text { berwirausaha }\end{array}$ & $\begin{array}{l}\text { Peserta diharapkan mampu } \\
\text { berpikir inovatif dan } \\
\text { mempunyai wawasan, } \\
\text { pengetahuan dalam menjawab } \\
\text { tantangan ekonomi ke depan } \\
\text { sehingga dapat menjadi lebih } \\
\text { berdaya saing. }\end{array}$ \\
\hline 2. & $\begin{array}{l}\text { Product Design \& } \\
\text { Concepts: } \\
\text { Wants vs needs }\end{array}$ & $\begin{array}{l}\text { 1. Pengertian want, need, dan } \\
\text { demand. } \\
\text { 2. Teknik mengumpulkan } \\
\text { kebutuhan konsumen dan } \\
\text { cara mengukurnya. }\end{array}$ & $\begin{array}{l}\text { Peserta diharapkan mampu } \\
\text { membedakan makna needs } \\
\text { dengan wants, serta mampu } \\
\text { menangkap kebutuhan } \\
\text { konsumen. Begitu pula, } \\
\text { Peserta mampu memahami } \\
\text { cara pengukurannya. }\end{array}$ \\
\hline 3. & $\begin{array}{l}\text { Product Design \& } \\
\text { Concepts: } \\
\text { Kreativitas dan } \\
\text { inovasi }\end{array}$ & $\begin{array}{l}\text { 1. Hubungan antara kreativitas } \\
\text { dan inovasi terhadap } \\
\text { kewirausahaan. } \\
\text { 2. Teknik Pembangkitan ide } \\
\text { kreativitas. }\end{array}$ & $\begin{array}{l}\text { Peserta dapat memahami } \\
\text { teknik-teknik bagaimana cara } \\
\text { membangkitkan ide produk } \\
\text { baru }\end{array}$ \\
\hline 4. & $\begin{array}{l}\text { Product Design \& } \\
\text { Concepts: } \\
\text { Pengembangan } \\
\text { dan Seleksi } \\
\text { Konsep Produk }\end{array}$ & $\begin{array}{l}\text { 1. Pengembangan spesifikasi } \\
\text { dan fungsional dari produk. } \\
\text { 2. Penyusunan konsep produk } \\
\text { 3. Cara pemilihan konsep } \\
\text { juara. }\end{array}$ & $\begin{array}{l}\text { Peserta mampu memahami } \\
\text { pengertian dan proses berpikir } \\
\text { dalam menentukan spesifikasi } \\
\text { dan fungsional untuk produk } \\
\text { yang sedang dikembangkan. } \\
\text { Dan juga, peserta dapat } \\
\text { menyusun beberapa konsep } \\
\text { produk dan memilih sebuah } \\
\text { konsep untuk dikembangkan } \\
\text { lebih lanjut. }\end{array}$ \\
\hline 5. & $\begin{array}{l}\text { Product Design \& } \\
\text { Concepts: } \\
\text { Prototipe }\end{array}$ & $\begin{array}{ll}\text { 1. } & \text { Pengertian prototipe } \\
\text { 2. } & \text { Prototipe terfokus } \\
\text { 3. } & \text { Prototipe menyeluruh }\end{array}$ & $\begin{array}{l}\text { Peserta mampu } \\
\text { mengembangkan ide } \\
\text { rancangan prototipe, dan } \\
\text { mampu memilih serta } \\
\text { merealisasikan prototipe yang } \\
\text { tepat untuk dikembangkan. }\end{array}$ \\
\hline 6. & $\begin{array}{l}\text { Workshop Product } \\
\text { Design with } \\
\text { Fusion360 }\end{array}$ & $\begin{array}{ll}\text { 1. } & \text { Pengenalan Autodesk } \\
\text { Fusion360 } \\
\text { 2. } \\
\text { Membuat } 3 D \text { Model } \\
\text { menggunakan Metode } \\
\text { Hybrid } \\
\text { 3. Membuat Cinematic } \\
\text { Photorealistic Rendering }\end{array}$ & $\begin{array}{l}\text { Peserta mampu menggunakan } \\
\text { perangkat lunak untuk } \\
\text { membuat desain } 3 \text { dimensi } \\
\text { dari sebuah produk dan } \\
\text { membuat gambar photo } \\
\text { realistic render. }\end{array}$ \\
\hline
\end{tabular}




\begin{tabular}{|c|c|c|c|}
\hline No. & Pokok Bahasan & $\begin{array}{c}\text { Materi/ } \\
\text { Sub-Pokok Bahasan }\end{array}$ & KOMPETENSI \\
\hline 7. & $\begin{array}{l}\text { Traditional } \\
\text { Marketing Vs } \\
\text { Entrepreneurship } \\
\text { Marketing }\end{array}$ & $\begin{array}{l}\text { 1. Pengertian Traditional } \\
\text { Marketing dan } \\
\text { Entrepreneurship Marketing. } \\
\text { 2. Manfaat dan kelebihan dari } \\
\text { pemasaran entrepreneurship. } \\
\text { 3. Kecerdasan Emosional dalam } \\
\text { Entrepreneurship. }\end{array}$ & $\begin{array}{l}\text { Peserta dapat mengetahui } \\
\text { perbedaan dari pemasaran } \\
\text { konvensional dan pemasaran } \\
\text { kewirausahaan serta manfaat } \\
\text { dan kelebihan dari pemasaran } \\
\text { entrepreneurship di era MEA. }\end{array}$ \\
\hline 8. & $\begin{array}{l}\text { Mix Marketing 4P } \\
\text { atau 7P }\end{array}$ & $\begin{array}{l}\text { 1. Pengertian, manfaat dan } \\
\text { peran mix marketing. } \\
\text { 2. Penjabaran variabel mix } \\
\text { marketing. }\end{array}$ & $\begin{array}{l}\text { Peserta dapat merancang mix } \\
\text { marketing yang terintegrasi } \\
\text { untuk menghasilkan respons } \\
\text { yang diinginkan dalam pasar } \\
\text { sasaran. }\end{array}$ \\
\hline 9. & Branding & $\begin{array}{l}\text { 1. Pengertian dan objektif } \\
\text { strategi branding. } \\
\text { 2. Unsur pendukung dalam } \\
\text { strategi branding. } \\
\text { 3. Pengertian dan peran dari } \\
\text { Brand Equity, Brand } \\
\text { awareness dan Brand Image } \\
\text { dalam keberlangsungan } \\
\text { suatu usaha baru. }\end{array}$ & $\begin{array}{l}\text { Peserta mampu menerapkan } \\
\text { dan merancang strategi } \\
\text { branding sebagai tahapan } \\
\text { pertama pengelolaan usaha } \\
\text { yang baru, dimana dibutuhkan } \\
\text { beberapa cara promosi dan } \\
\text { pengenalan brand yang } \\
\text { khusus agar perjalanan } \\
\text { produk baru tersebut dapat } \\
\text { tepat sasaran dengan waktu } \\
\text { dan biaya yang lebih efektif. }\end{array}$ \\
\hline 10. & E-Commerce & $\begin{array}{l}\text { 1. Pengertian, proses dan } \\
\text { perspektif dari e-commerce. } \\
\text { 2. Jenis-jenis e-commerce. } \\
\text { 3. Dampak dan faktor } \\
\text { keberhasilan e-commerce } \\
\text { terhadap dunia bisnis. } \\
\text { 4. Manfaat e-commerce. } \\
\text { 5. Strategi pemasaran dalam e- } \\
\text { commerce. }\end{array}$ & $\begin{array}{l}\text { Peserta mampu } \\
\text { mengaplikasikan rencana } \\
\text { bisnis ataupun usaha yang } \\
\text { sudah berjalan dengan } \\
\text { memanfaatkan strategi } \\
\text { pemasaran dalam } e^{-} \\
\text {commerce sehingga } \\
\text { kedepannya dapat diperoleh } \\
\text { efisiensi dalam berbagai } \\
\text { aspek manajemen. }\end{array}$ \\
\hline
\end{tabular}

Selain itu, Teknik Industri Universitas Tarumanagara sedang menjajaki untuk mengembangkan inovasi dan inkubator bisnis berbasis teknologi maupun membantu industri/pengrajin kecil dalam meningkatkan proses bisnisnya ataupun profitnya. Jejaring yang perlu dibangun, antara lain: angel investor, technological entrepreneur, korporasi, technopark, dan lembaga pemerintah lainnya, dalam menunjang akses keuangan dan bantuan teknis. Kunci keberhasilan dari inovasi dan inkubator teknologi adalah jumlah bisnis startup atau UMKM berbasis teknologi yang dihasilkan, dan jumlah teknologi/produk yang didaftarkan atas hak kekayaan intelektual.

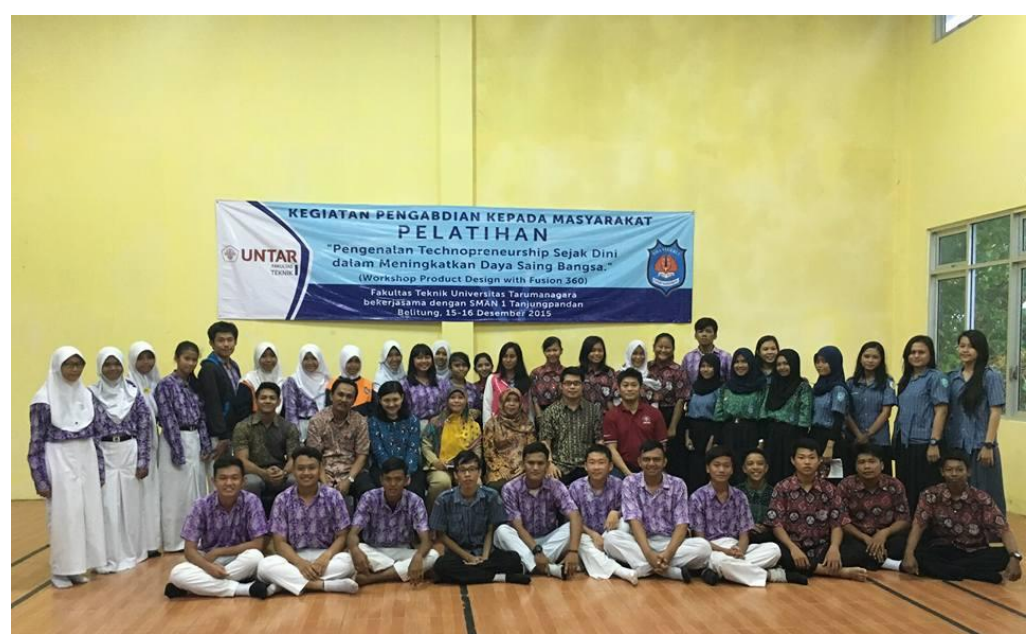

Gambar 7. Pelaksanaan Pengabdian kepada Masyarakat di SMAN 1 Tanjung Pandan Belitung, 2015 


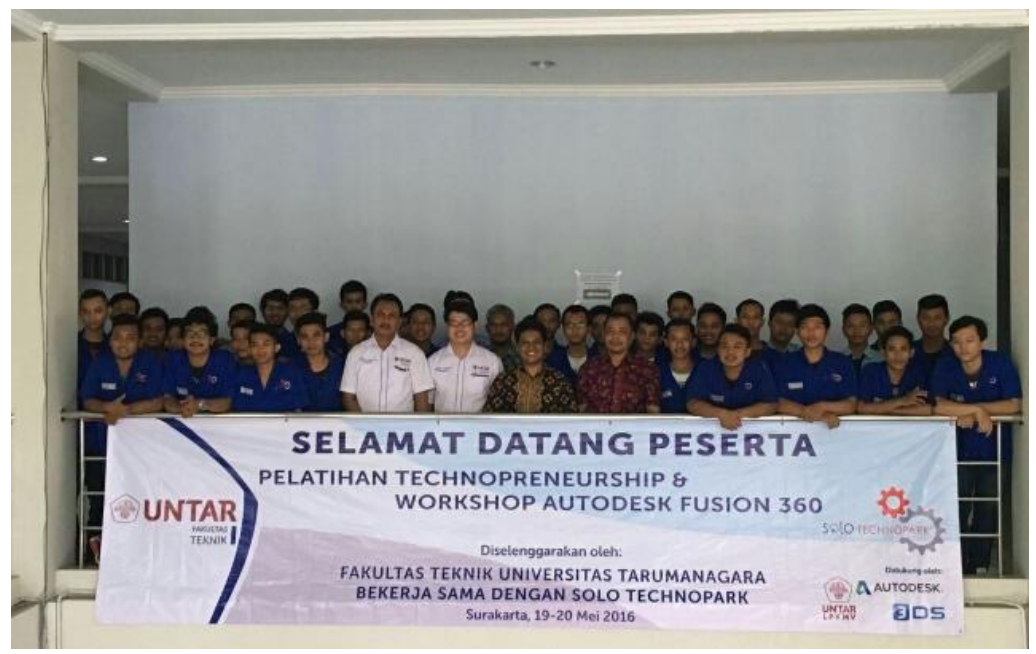

Gambar 8. Pelaksanaan Pengabdian kepada Masyarakat di Solo Technopark, 2016

\section{Kesimpulan}

Universitas memegang peranan yang penting dalam meningkatkan technopreneur di Indonesia. Akademisi atau peneliti sebagai agen pengembang maupun difusi inovasi dan teknologi berbasis riset unggulan, bertanggung jawab untuk mendiseminasikan pendidikan entrepreneurship berbasis teknologi secara luas. Difusi teknologi dan pendidikan technopreneurship akan dapat meningkatkan potensial effect tumbuh-kembangnya innovative-technological startup. Penekanan dari pendidikan technopreneurship adalah kreativitas dan kemampuan berinovasi yang berkelanjutan. Di samping itu, universitas dapat terlibat secara langsung membangun inkubator teknologi maupun berkolaborasi dengan stakeholder lainnya, seperti: angel investor, technological entrepreneur, korporasi, dan pemerintah, dalam menciptakan ekosistem bisnis berbasis teknologi. Inkubator bisnis berbasis teknologi akan dapat mempercepat komersialisasi hasil inovasi atau invensi yang dihasilkan dari riset universitas.

\section{Referensi}

Amboala, T. \& J. Richardson. (2016). Technological Framework Commercialization Entrepreneurship for University of Information Technology. Issues in Informing Science and Information Technology, 13, 279-290.

Direktorat Akademik.

(2008).

Technopreneurship. Direktorat Jendral Pendidikan Tinggi: DIKTI. [Online, diakses pada 19 Februari 2016].

Hakim, Arman \& Hermawan Kartajaya. (2012).

Supply Chain Economic: Rekonstruksi
Inovasi Daya Saing Increasing Return. Yogyakarta: Penerbit ANDI.

Horth, David Magellan \& Jonathan Vehar. (2014). Becoming a Leader Who Fosters Innovation. Center for Creative Leadership. [Online, diakses pada 12 Februari 2014].

Loh, Leslie. (2013). Learn to Be a Technopreneur and Create Your Tech Startup. The Startup Ecosystem. [Online, diakses pada 19 Februari 2016].

Mian, Sarfraz A.. (1997). Assessing and Managing The University Technology Business Incubator: An Integrative Framework. Journal of Business Venturing, 13, 251-285.

Miller, et.al.. (2012). Innovation Leadership Study. Capgemini Consulting: United Kingdom. [Online, diakses pada 25 Maret 2014].

Mowery, D. C. \& S. Shane. (2002). Introduction to The Special Issue on University Entrepreneurship and Technology Transfer. Management Science, 48(1), v-ix.

OECD. (1997). Technology Incubators: Nurturing Small Firms. Head of Publications Service, OECD, 2, Rue AndréPascal, 75775 Paris Cedex 16, France. [Online, 19 Februari 2016].

PII. (2016). Materi Program Pembinaan Profesi Insinyur. Sekretariat BKTI-PII: Jakarta

Rubin, et.al.. (2015). Knowledge flow in Technological Business Incubators: Evidence from Australia and Israel. Technovation. 